\title{
Análise de integridade física de barragem de terra por meio de eletrorresistividade no município de Cordeirópolis - SP.
}

Pedro L. Camarero, UNESP

César A. Moreira, UNESP

Glauber M. L. Vieira, UNESP

\section{Copyright 2014, SBGf - Sociedade Brasileira de Geofísica}

Este texto foi preparado para a apresentação no VI Simpósio Brasileiro de Geofísica, Porto Alegre, 14 a 16 de outubro de 2014. Seu conteúdo foi revisado pelo Comitê Técnico do VI SimBGf, mas não necessariamente representa a opinião da SBGf ou de seus associados. É proibida a reprodução total ou parcial deste material para propósitos comerciais sem prévia autorização da SBGt.

\section{Resumo}

Barragens são estruturas que represam rios e córregos para diversas finalidades. Essas estruturas geralmente precisam ser robustas devido a força de represamento e os altos valores de carga de água acumulados. A constante manutenção dessas estruturas é imprescindível, uma vez que um acidente eventual pode gerar danos de proporções catastróficas. Esse estudo apresenta uma alternativa barata, de simples e rápida aplicação para analises de integridade física de barragens de terra. Os resultados são apresentados a partir de imagens geofísicas, indicando alto contraste de propriedades em zonas de possíveis falhas e/ou piping (menor resistividade aparente).

\section{Introdução}

O represamento de corpos d'água é realizado desde os primórdios da humanidade para diferentes fins. As primeiras barragens e diques são datados a mais de 4 mil anos. Dentre as várias funções das barragens, os principais propósitos são a estocagem de águas para irrigação de culturas agrícolas, e mais recentemente, na era moderna a geração de energia elétrica. Inicialmente as barragens eram construídas a partir de um aterro, ou seja, um amontoado de terra e solo, e eventualmente blocos de rochas e madeiras. Muitas vezes não havia um estudo prévio nem a execução de um projeto civil. Com o aumento da demanda por energia constante no início do Século $X X$ houve a necessidade de obras cada vez maiores e mais ousadas. Grandes rios começaram a ser represados e juntamente com esse aumento de demanda, foi desenvolvido e aperfeiçoado técnicas específicas de construção de superestruturas de barragens. O crescimento do número de barragens, também trouxe o aumento de problemas e acidentes relacionados com a construção e manutenção dessas estruturas. Todas as barragens necessitam de manutenção constante e geralmente as barragens de menor porte e impacto não apresentam essa manutenção constante. Os principais problemas associados as barragens são: piping (erosão interna pontual), falhas de execução de projeto, galgamento da barragem e escolha de matérias de empréstimo indevida. O presente trabalho visa utilizar a partir de métodos indiretos de investigação aplicando o método da eletrorresistividade na investigação de possíveis falhas estruturais no corpo de barragem de terra de pequeno porte no município de Cordeirópolis - SP. A área de estudos esta inserida no contexto geológico da Bacia Sedimentar do Paraná. A geologia local é composta principalmente por rochas básicas vulcânicas da Formação Serra Geral, com manifestações vulcânicas datadas em Eocretácio (NARDY et al., 1999). Segundo Sousa (2002), a forma de ocorrência da Formação Serra Geral na região leste do Estado de São Paulo é sobre a forma de diques e sills de diabásios ou basaltos, além de alguns derrames pouco espessos. O solo de alteração das rochas é um solo argiloso do tipo Latossolo. Esse solo de alteração é o principal material de empréstimo utilizado no corpo da barragem. A partir desse contexto é apresentado o estudo geofísico.

\section{Metodologia/ Problema Investigado}

No método da Eletrorresistividade, correntes elétricas artificialmente geradas são introduzidas no solo, por intermédio de um par de eletrodos denominados de $\mathrm{A} e$ $B$, e as diferenças de potencial resultante são medidas na superfície por meio de outro par de eletrodos, denominados C e D na área de influência do campo elétrico. Os desvios do padrão de diferenças de potencial esperado do solo homogêneo fornecem informações sobre a forma e as propriedades elétricas das heterogeneidades de superfície (KEAREY et al., 2002). A partir da intensidade de corrente que percorre o subsolo (I) a geometria da disposição dos eletrodos $(K)$ e a diferença de potencial medido pelos eletrodos receptores $(\Delta V)$, é possível calcular o valor da resistividade aparente, devido a heterogeneidade do meio equação:

$$
\rho_{a}=K . \Delta V / I \Omega . \mathrm{m} \text {. }
$$

A unidade da resistividade aparente é o ohm.m, a diferença de potencial é medida em milivolt $(\mathrm{mV})$, a intensidade de corrente é medida em miliampère $(\mathrm{mA})$ e o coeficiente geométrico $K$ em metros. No caso de barragens de terra, o contraste de propriedades físicas de materiais como água e solo, podem indicar anomalias na estrutura. No local de estudos foram realizadas três linhas geofísicas, espaçadas a 3 metros. O sentido de caminhamento foi de Nordeste para Sudoeste. O arranjo utilizado foi Wenner com 53 eletrodos espaçados a cada 2 metros. Cada linha teve 104 metros de comprimento, o que permitiu cobrir toda a extensão da barragem e forneceu uma resolução de aproximadamente 17 metros de profundidade. A linha 1 foi locada mais próximo à jusante, enquanto a linha 3 , mais próxima à montante (Figura 1). 
O equipamento utilizado para esse estudo foi o resestivímetro ABEM Terrameter LS de 64 canais e potência de 250W (Foto 1).

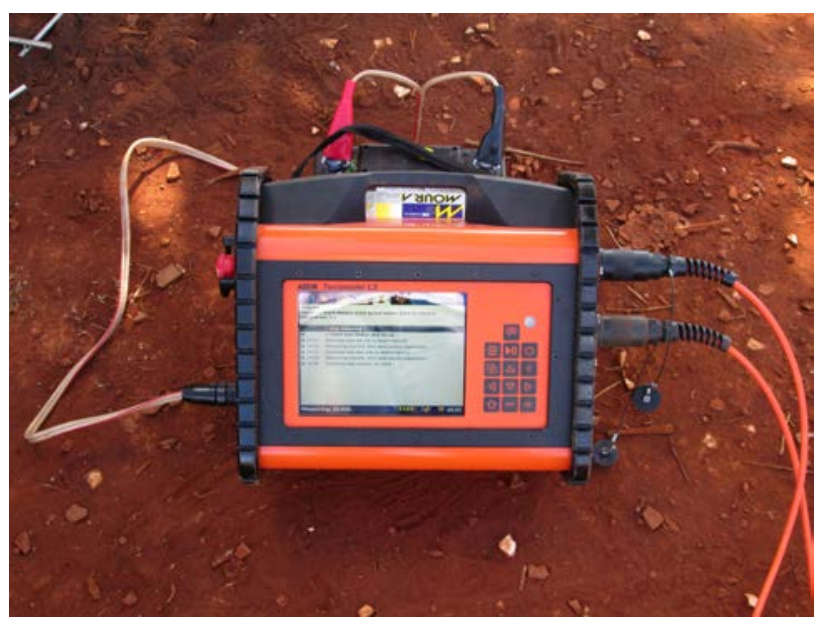

Foto 1 -Resestivímetro ABEM Terrameter LS.

\section{Resultados}

Os dados interpretados foram processados no software RES2DINV, apresentados sob a forma de seções distância x profundidade (LOKE; BAKER, 1996), sob a forma de modelo de inversão em termos de resistividade elétrica. Esse programa é projetado para processamento de grandes conjuntos de dados em duas dimensões, adquiridos por meio da técnica de caminhamento elétrico. O processo de inversão consiste em uma série de blocos retangulares, a disposição dos blocos é ligada à distribuição dos pontos dos dados na pseudo-seção, ou seja, seção gerada pelos dados de campo em profundidade teórica. A distribuição e tamanho dos blocos são gerados automaticamente pelo programa conforme a distribuição dos pontos de dados. A profundidade da linha inferior dos blocos é definida para ser, aproximadamente, igual à profundidade equivalente de investigação de pontos com o maior espaço entre eletrodos (EDWARDS, 1977). A sub-rotina de modelagem direta é usada para calcular os valores de resistividade aparente e uma técnica de otimização nãolinear por mínimos quadrados é usada para a rotina de inversão (DEGROOT-HEDLIN; CONSTABLE 1990, LOKE; BARKER, 1996). O resultado é apresentado sob a forma de seção com distância versus profundidade em termos de pseudo-seção, seção calculada e modelo de inversão.

No trabalho foram levantados mais de 300 metros de caminhamento a partir do arranjo Wenner. Em geral, os tons de cores vermelho/amarelo apresentam valores de maior resistividade, enquanto que os tons de cores mais frias, como azul, apresentam valores de menor resistividade. Todas as linhas captaram o vertedouro da barragem. No caso da barragem de estudos esse vertedouro é feito de concreto, e devido ao grande contraste de propriedades físicas com o material do corpo da barragem, em todas as imagens essa estrutura acaba sendo bem visível e facilmente identificado. O vertedouro apresenta um formato de tronco de cone, com sua cavidade superior menor que a inferior. Em geral, é possível visualizar o vertedouro em subsuperfície entre 62 e 64 metros, e mais profundamente entre 48 e 72 metros das linhas. O concreto do vertedouro apresenta uma resistividade maior, marcado na figuras por tons de cores menos frias, como amarelo e vermelho. A Linha 1, disposta mais próxima a jusante, apresenta uma zona de baixa resistividade, com valores inferiores a $100 \Omega . \mathrm{m}$ disposta horizontalmente entre 19 e 45 metros e na vertical entre 4 e 8 metros de profundidade (Figura 2).

Essa mesma zona de baixa resistividade é visível na Linha 2 entre o mesmo intervalo, porém com uma resistividade um pouco menor no centro da anomalia (Figura 3).

E finalmente a Linha 3 , que é disposta mais próxima a montante, apresenta a mesma anomalia, porém um pouco maior que na Linha 1 e 2 e focos de resistividade

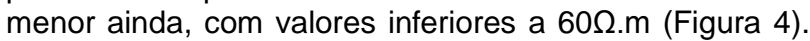
$\mathrm{Na}$ Linha 3 a anomalia se distribui horizontalmente entre 18 e 45 metros, e verticalmente entre 2 e 8 metros de profundidade.

\section{Discussões e Conclusões}

A zona de baixa resistividade apresentada em todas as linhas pode ser considerada uma zona de percolação de água, onde é possível visualizar uma maior influência próxima a montante (Linha 3 , onde a zona apresenta menor resistividade, e o solo está mais saturado). $\mathrm{Na}$ Linha 2 é notada uma resistividade um pouco maior em relação a Linha 3 , provando que o solo no local da infiltração é menos saturado. A Linha 1 apresenta o uma resistividade menor ainda em relação a Linha 3 , mostrando que quanto mais distante da montante, menor o poder de infiltração da água e consequente saturação do solo. Os dados mostram que quanto mais próximo a montante da barragem, maior é a susceptibilidade do corpo da barragem, comprovando a necessidade de um maior cuidado com a porção à montante da barragem. A evolução da zona de menor resistividade, considerada como uma zona de percolação hídrica e passível de erosão interna é apresentada na imagem a seguir (Figura 5).

O método geofísico de eletrorresistividade é um método pouco usual para inspeção de corpos de barragens de terra. Case (2012) demonstrou a eficiência do método em barragens de terra de Oklahoma. O atual estudo comprova que o método da eletrorresistividade é uma ótima alternativa de investigação. O contraste de propriedades físicas do solo com água é visível e marcante. Por tanto é possível afirmar que o estudo apresenta resultados satisfatórios mostrando a eficiência do método, mesmo não sendo o mais usual, e provando que a geofísica representa uma alternativa barata para manutenção de corpos de barragens de terra. Esse estudo pode ser amplamente aplicado em barragens de diferentes natureza, seja para decantação de resíduos na mineração, estocagem de água para irrigação/abastecimento ou até mesmo geração de energia. 


\section{Referências}

Case, J. S.; 2012. Inspection of Earthen Embankment Dams Using Time Lapse Electrical Resistivity Tomography. A Thesis of Master of Science. Department of Civil Engineering of The University of Mississippi. 97p.

Degroot-Hedlin, C.; Constable, 1990. S. Occam`s Inversion to Generate Smooth, two-dimensional models form magnetotelurric data. Geophysics. Vol. 55: 1613-1624.

Edwards, L. S. 1977. A modified pseudosection for resistivity and induced polarization. Gephysicis. Vol. 42: 1020-1036.

Kearey, P.; Brooks, M.; Hill, I. 2002. An Introduction to Geophysical Exploration, Third Edition, Wiley-Blackwall Science Ltd. 2002. 272.

Loke, M. H.; Baker, R. D. 1996. Rapid Least-Squares Inversion of Apparent Resistivity Pseudosections by Qausi-Newton Method. Geophysical Prospecting. Vol. 44: 131-152.
Milani, E. J. 1997. Evolução tectono-estratigráfica da Bacia do Paraná e seu relacionamento com a geodinâmica fanerozóica do Gondwana sul-ocidental. 2 v. Tese (Doutorado) - Universidade Federal do Rio Grande do Sul, Porto Alegre.

Nardy, A. J. R. et al. 1999. Aspectos geológicos e estratigráficos das rochas vulcânicas ácidas do Membro Chapecó. In: SIMPÓSIO DE GEOLOGIA DO SUDESTE, São Pedro. Resumos... São Pedro: SBG, Vol.1: 68.

Sousa, M.0.L. 2002. Evolução tectônica dos altos estruturais de Pitanga, Artemis, Pau d'Alho e Jibóia - centro do Estado de São Paulo. 227 f. Tese (Doutorado em Geociências) - Instituto de Geociências, Universidade Estadual Paulista, Rio Claro.

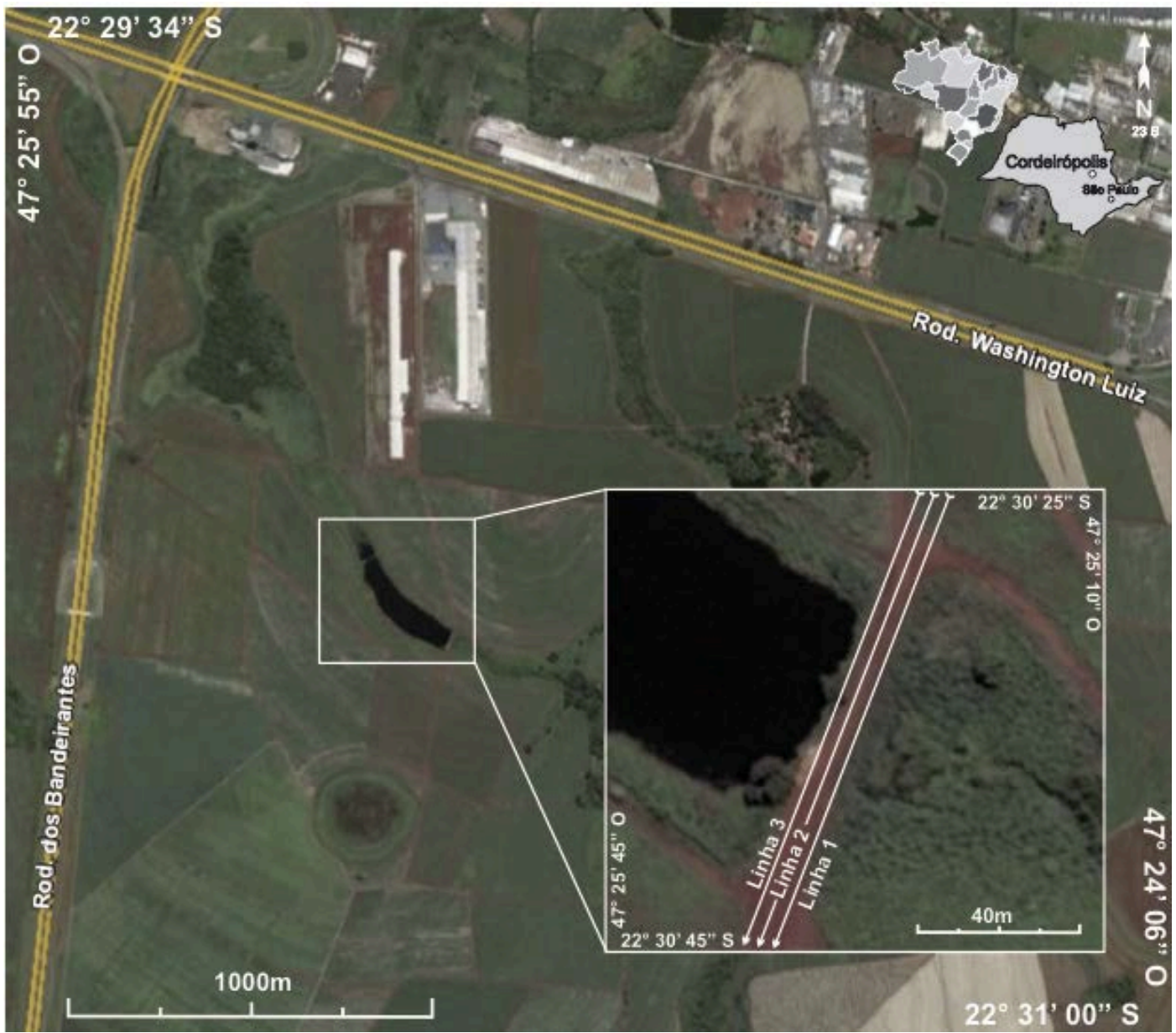

Figura 1 -Local de estudos com a disposição das linhas de aquisição de dados. 

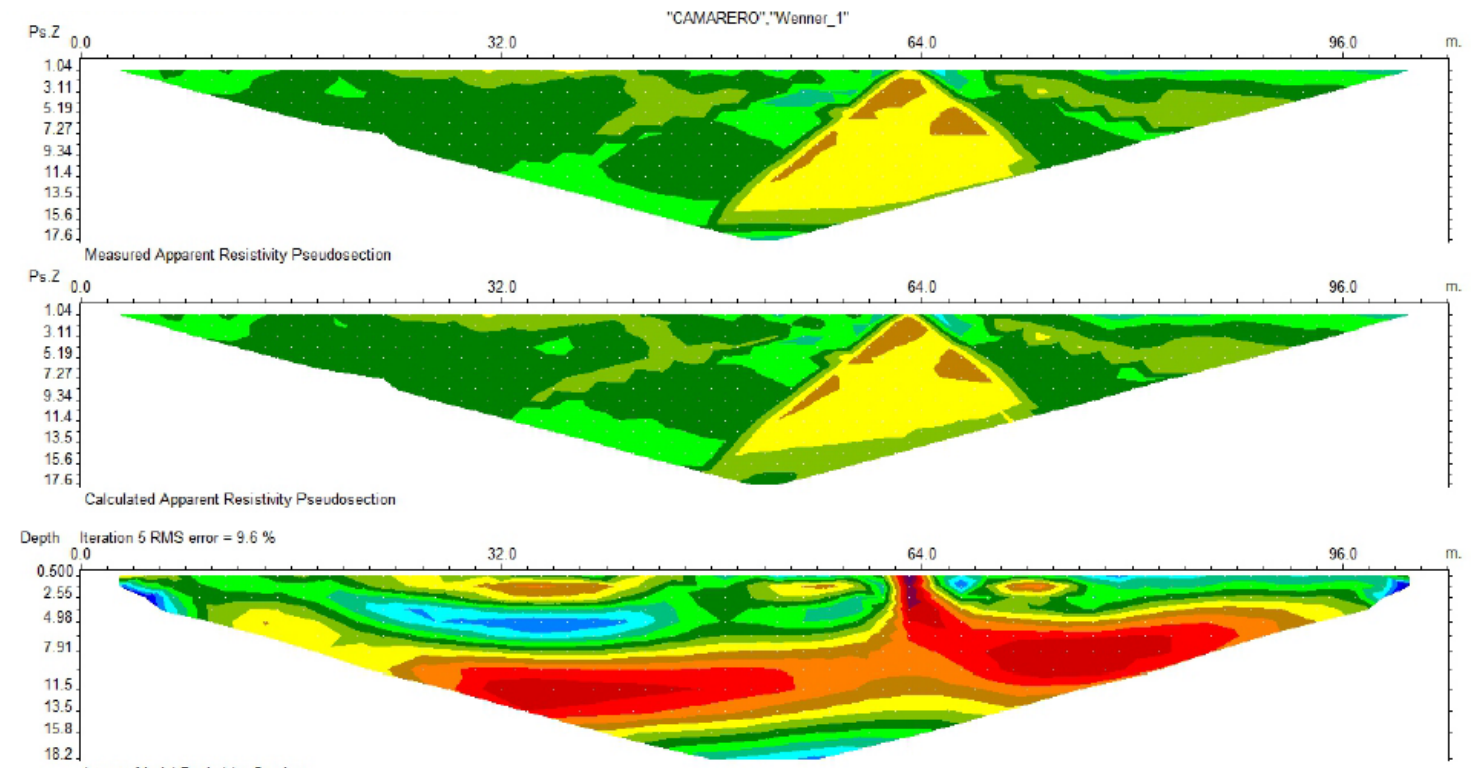

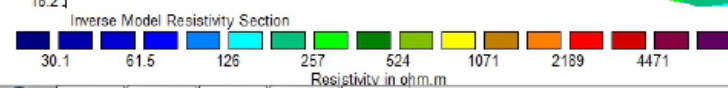

Figura 2 -Linha 1, disposta à jusante.
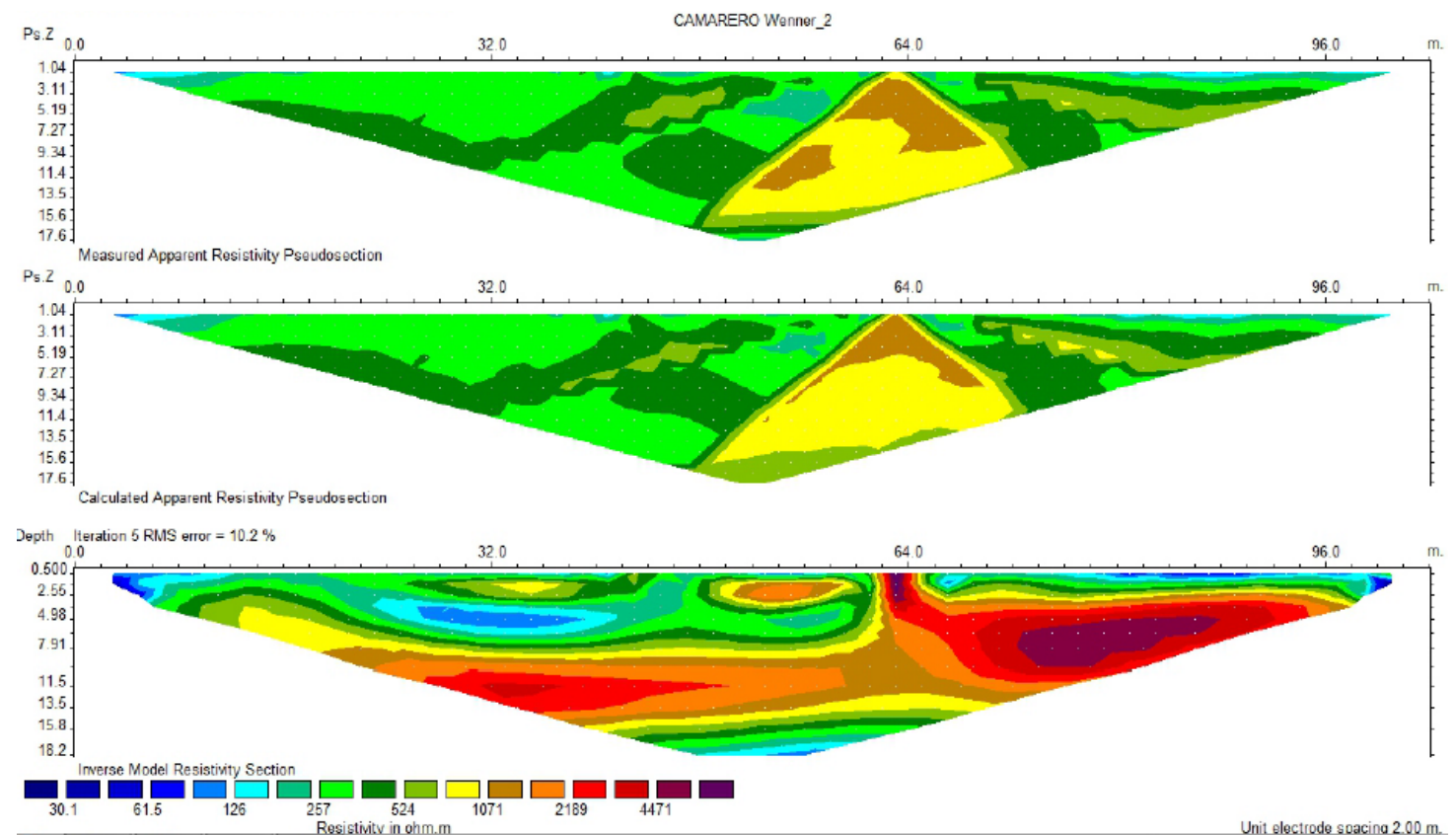

Figura 3 -Linha 2, posição intermediária. 

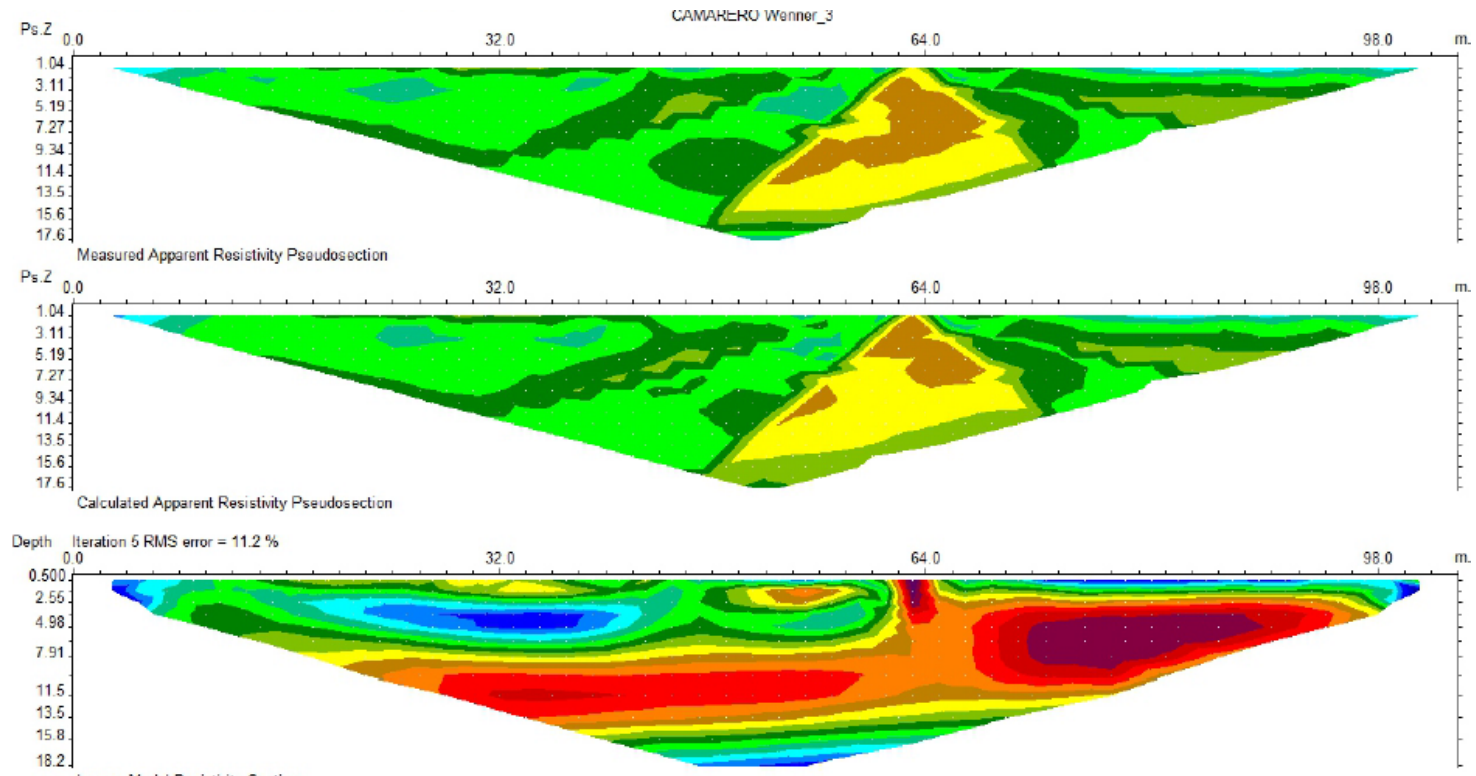

\section{$\square_{30.1}^{\text {Irverse Model Resistivity Section }} \square_{61.5}^{\square} \square \square_{257}^{\square} \square \square_{1071} \square_{2189} \square_{4471} \square$}

Unit electrode spacina $2.00 \mathrm{~m}$.

Figura 4 -Linha 3, disposta à montante.
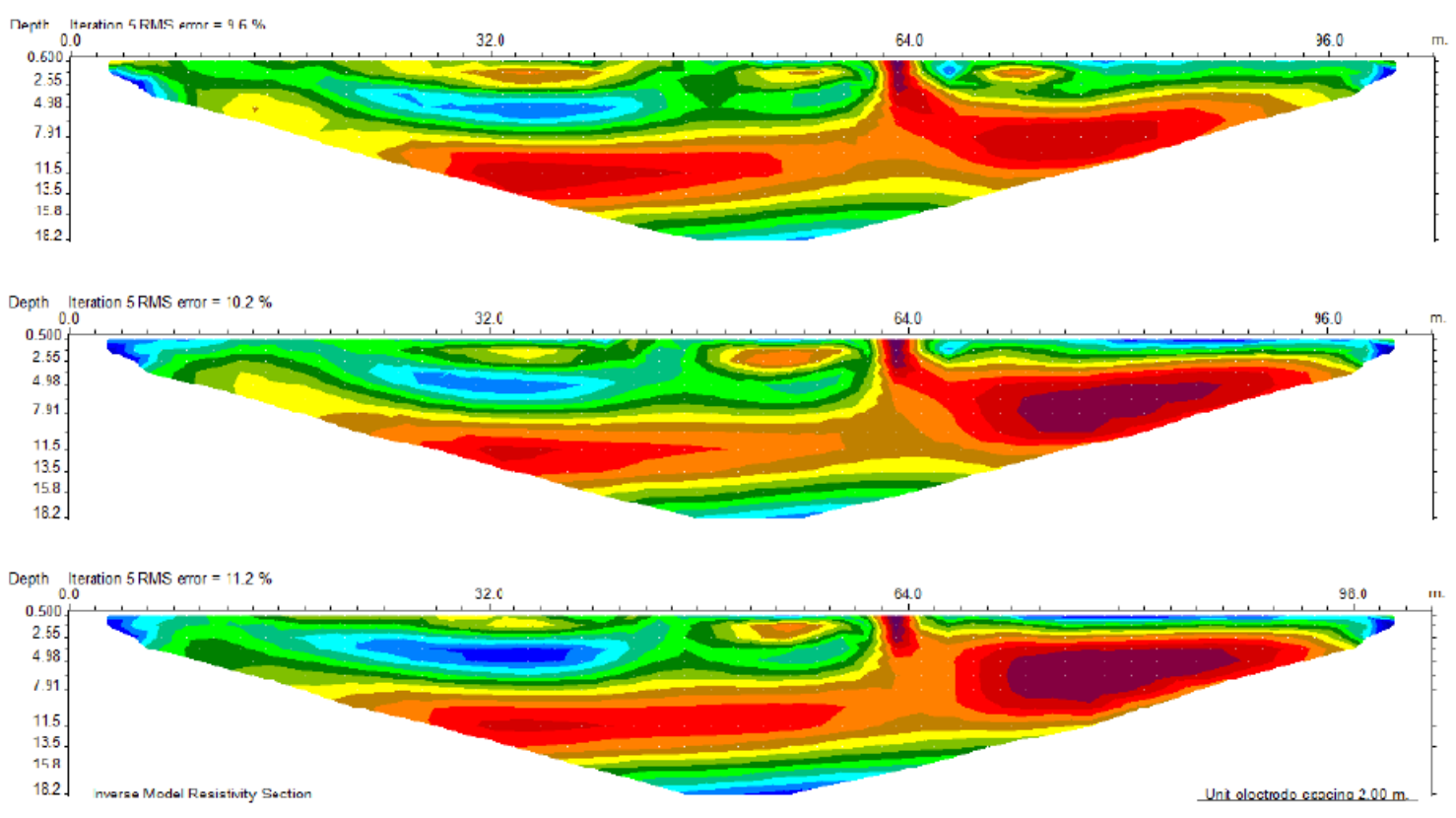

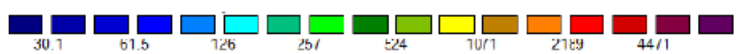

Figura 5 -Evolução da zona de menor resistividade. De cima para baixo: Linha 1, Linha 2 e Linha 3. 